\title{
Study and Analysis on the Factors of Site Selection in Large Oil Seal Cavern at Home and Abroad
}

\author{
Sui YuXuan ${ }^{1, ~ a, ~ Z h a o ~ D o n g F e n g ~}{ }^{2, b}$ Zhang $\mathrm{Li}^{3, \mathrm{c}}$ and Chen JiaWei ${ }^{4, \mathrm{~d}}$ \\ 'Zhejiang Ocean University, 1 Haida South Road, Lincheng street, Dinghai District, Zhoushan City, \\ Zhejiang Province, China \\ 2Zhejiang Ocean University, 1 Haida South Road, Lincheng street, Dinghai District, Zhoushan City, \\ Zhejiang Province, China \\ ${ }^{3}$ Zhejiang Ocean University, 1 Haida South Road, Lincheng street, Dinghai District, Zhoushan City, \\ Zhejiang Province, China \\ ${ }^{4}$ Zhejiang Ocean University, 1 Haida South Road, Lincheng street, Dinghai District, Zhoushan City, \\ Zhejiang Province, China \\ a331629811@qq.com, b409350641@qq.com , ckl_vin@163.com, d2538561519@qq.com
}

Keywords: underground water seal cavern, site selection, large oil seal cavern

Abstract.as an important form of petroleum reserve, underground water seal cavern has the advantages of safety and low environmental protection cost. So water sealed underground structure of the site selection is a vital step, this article through to the domestic and foreign water seal the location of the underground structure analysis, this paper, the location of the important factors for the future of domestic large oil seal the locations of the underground structure to present an opinion, for the government and enterprise in the field of site construction and provide reference for long-term planning, etc

\section{Introduction}

Energy security has always been the focus of the national security policies of various countries, and the establishment of a complete set of petroleum strategic reserves is an important component of the grand strategy of energy security. Due to its advantages of safety, environmental protection and low cost, underground water seal cavern has become an important form of petroleum reserve. With the development of economy and the changing international environment, petroleum energy reserve has become an important factor affecting national economic, political and military security. In this paper, based on the investigation of the existing large oil seal caverns at home and abroad, the author puts forward some Suggestions on the site selection of large oil seal caverns in the future. For the government and enterprises in the field of site selection and construction and long-term planning.

\section{Site Selection of Large Oil Seal Caverns in the United States, Germany and France}

The US, Germany, France and the government have followed the following points for the location of large oil water-sealed caverns: High security and reliability. It is most convenient to store and transport oil and oil. Geological and geographical conditions are most suitable. Due to the high requirements of engineering address and hydrogeological conditions, it is important to transport oil conveniently and quickly. However, it is difficult to use the existing railway, long-distance transportation pipeline and other storage and transportation facilities in the large-scale oil seal cavern. Therefore, the choice of geographical location greatly affects the economic cost of oil depot operation and maintenance. So water sealed underground structure should be according to the contingency reserve oil processing requirements as well as the conditions, transportation, oil discharge, should select the refinery is relatively concentrated, have to rely on oil pipeline network oil terminal area. Secondly, the choice of storage location also needs to take into account the areas with high demand for oil products and high concentration of processing and importing crude oil. ${ }^{[1]}$ 
The governments of the United States, Germany, France and the three countries all adopted the centralized layout. In the United States, for example, oil reserves are concentrated along the gulf coast. The main reason is that 1 . The gulf coast region has superior geographical conditions suitable for underground storage of crude oil. Located in Texas, the largest petrochemical industrial center in the United States, it is one of the world's largest petrochemical industrial zones.3. Convenient transportation conditions, dense pipeline network throughout the country, as well as the main entrance to imported crude oil, the distribution of crude oil is very fast and convenient.

\section{Location of Japan's Large Oil Seal Caverns}

Japan has three underground reserve bases ${ }^{[2]}$, respectively, Kuzi, Kikuma and Kushikino. Kuzi and Kikuma base is located in the foundation rock stratum of granite during the cretaceous period. The granite is hard and dense, and there are few cracks in the rock body. Different from the above two bases, Kushikino base is located in the area of the neocene and quaternary volcanism. String of wild wood base selection in lithologic better dig tunnels in the Miocene volcanic debris group, because there is no obvious lithologic good pyroclastic rock of wrong layer and joint, can be in a certain extent avoid magmatic rocks along the magma surface between layer and layer fracturing, which destroys the base. According to the site selection of the underground reserve base in Japan, the site selection of the underground water-sealed cavern can choose the granite stratum with good lithology.

\section{Site Selection of Large Domestic Oil Water-sealed Caverns}

In the $1970 \mathrm{~s}$ began to research in $\mathrm{China}^{[3]}$, the construction of underground water seal oil underground structure, to prevent the imported oil supply disruptions and set up a moderate amount of oil reserves with experimental successively in Xiang Shan, Zhejiang province and Shandong Huang Dao respectively established two crude, later because of the large floating roof tank is widely used, combined with the reasons, Huang Dao water sealed underground oil tanks is not commonly used, only the XiangShan diesel library has been in operation. Until the end of last century, due to the massive imports of liquefied petroleum gas in our country, the storage way to reuse, coastal areas in China, Huizhou, Zhanjiang, Shantou, Ning Bo is established, such as underground water seal underground structure ${ }^{[4]}$.

Huang Dao LPG underground storage project, the storage area is located in the north margin of Jiao Nan Tai Long, a low-mountain and hilly landform. The main body of the cave is located on the south side of Long $J i$ mountain in the east-west direction. Surrounding rock of underground structure is given priority to with granite gneiss, surrounding rock is given priority to with II, III class. Underground structure within the scope of development there are several faults and fault fracture zone, joint development, main structural plane have 5 groups, give priority to with steep dip Angle joint, underground structure structural plane development exists obvious difference in different areas.

Huizhou state storage underground water seal caverns ${ }^{[5]}$, the site of which is under the jurisdiction of Ming Shan town, Hui Dong county, the storage area plane is irregular polygon .Reservoir area and the surrounding to low mountain area, the high terrain north south is low, the surface is residual deposit more, vegetation growth, according to the grass, deep through difficulties, reservoir area and its adjacent area is located in the southwest edge of south China orogenic belts, the second-order tectonic units the southeast coastal fault fold belt, library site is in the coast mountains block, the reservoir brittle fracture structure, the cash for the fracture and the joint structure. There are quartz vein veins and diabase veins in the reservoir.

\section{Site Selection According to China's Situation}

China's dependence on oil imports rose to 72.3 percent in 2017, overtaking The US as the world's largest importer of crude oil. However, China's imported oil is transported by oil tanker except 
through pipelines. China accounts for 19 percent of the world's 4,01m barrels of crude oil shipped per day in 2017.

Figure 1 Distribution of crude oil import by sea in $2017^{[6]}$

\section{Distribution of crude oil import by sea in 2017}

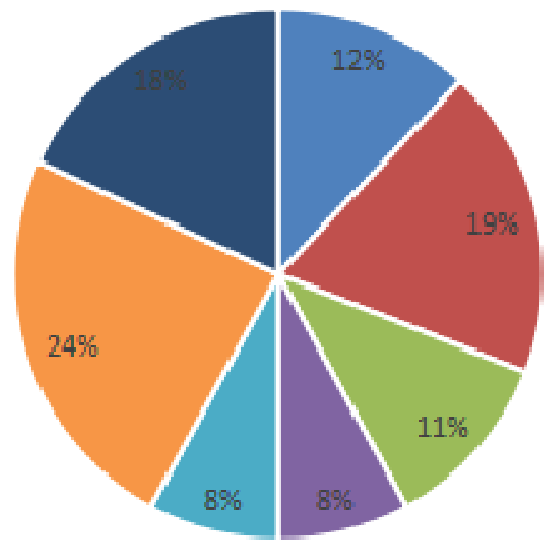

- America

- China

- India

- Japanese

- Korea

Europe

- else

China's large wharves are mainly distributed in two areas: coastal areas and Yangtze river basin. Oil refineries and other petroleum processing bases are mainly located in the oil fields, near large seaports and Yangtze river wharves. Therefore, it is advisable to find suitable places in coastal cities as shown in Figure 2 for underground water seal caverns.

Figure 2 Distribution map of coastal cities in China

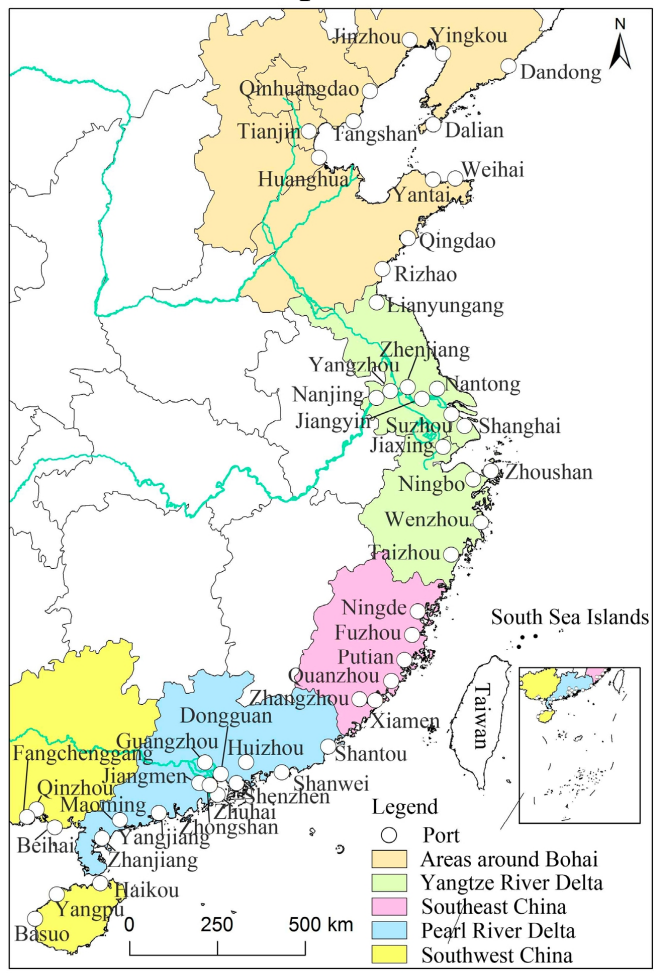

From existing data, the main fault zone of the west coast of the Pacific rim region to roughly $\mathrm{NE} 20^{\circ}$ to $30^{\circ}$, the study area have regional fault zone - the Tan Lu fault zone through, so within the scope of the study area is more strong cutting the regional fault zone, fault zone set up to avoid here.

\section{Conclusion}

In this paper, based on the existing underground water underground structure of Chinese and foreign coastal areas of our country underground water seal location area for building a underground 
structure stability, rock type, plate fracture zone and so on three aspects of qualitative evaluation, the following conclusions:

1.According to the result of the evaluation of regional stability, is suitable for construction of underground water seal of underground structure in coastal areas are mainly distributed in Liaoning, Hebei, Shandong, Anhui, Jiangsu, Zhejiang, Fujian, Guangdong, Hainan, Guangxi and other regions, in other provinces also have a small amount of distribution.

2.According to Japanese site selection bias towards the study of rock, the location should also be unexpectedly, as far as possible the choice of underground strata for the granite, granodiorite, granite gneiss, gneiss, tuff, sandstone, limestone and so on, in rock mass and rock mass quality grade for more I, II, III class best.

3.According to the tectonic fault zone, the distribution of shows the location of the underground water underground structure is unfavorable in Harbin east, Fuzhou and Guangzhou east, Hefei Lu Jiang Tan Cheng - Shenyang area, Tianjin, Beijing area.

4.At present our country built underground water seal of underground structure in addition to shantou basically conforms to the above conclusions, this article analysis the result tallies with the actual project site selection, embody the research methods and the rationality of the results in this paper.

In this paper, the results of the study provides reference for the planning and site selection of underground water underground structure and the method, but for wide scope of the study area, restricted by basic data, the results have some room to improve on the accuracy, the specific location also have to consider more field situation. In addition, there are many influencing factors in the requirements of site selection, and the influence of atmospheric environment and groundwater corrosion should be considered in future studies

\section{References}

[1] Zhu RUI Feng Chun ping, The strategy and layout of China's oil reserves at the beginning of the twenty-first Century. Tehneo-Eonomics in Petrochemicals Twenty-third Vol. second April 2007.

[2]Zhu Jian Ming Lu You, Analysis of rock mass characteristics of underground oil storage in Japan. Chinese Journal of Underground Space and Engineering Vol. 4 Apr. 2008.

[3] Development and Application of Construction Technologies for Underground Water-sealed Energy Storage Caverns HONG Kairong Tunnel Construction vol.34 No3 Mar. 2014

[4] Regional Stability Of Underground Water Sealed Storage Caverns Around Western Pacific Coastal Area In China, WANG Zhang qiong YAN E'chuan JI Huibin SONG Kun Journal of Engineering Geology 1004-9665 /2013 /21(4) -0626-08

[5] Analysis and evaluation of surrounding rock stability of underground water sealed oil storage caverns in Huizhou, Yang Feng Second chapters and tenth pages.

[6] China's industrial information 2018 China's crude oil import volume, sea freight volume and industry development trend Figure 1 